\title{
IN VIVO AND IN VITRO INTERACTION STUDIES OF ENALAPRIL WITH FLURBIPROFEN ON CARRAGEENAN INDUCED INFLAMMATION RATS (CIIR)
}

\author{
SAFILA NAVEED ${ }^{* 1,2}$ NAJMA SULTANA ${ }^{1}$, AND M. SAEED ARAYNE 3 \\ ${ }^{I}$ Research Institute of Pharmaceutical Sciences, Faculty of Pharmacy University of Karachi, Karachi-75270. Pakistan \\ ${ }^{2}$ Faculty of Pharmacy, Jinnah University for Women, Karachi. Pakistan \\ ${ }^{3}$ Department of Chemistry, University of Karachi, Karachi
}

\begin{abstract}
Both ACE inhibitors and non steroidal anti-inflammatory drugs (NSAIDs) are prescribed together in the elderly as different diseases may occur together. In vivo and in vitro interaction studies of ACE inhibitor (enalapril) was carried out with commonly used NSAID, flurbiprofen in carrageenan induced inflammation (CIIR) rats to check the anti-inflammatory response of NSAIDs in presence of enalapril and alone. In present study, altered anti-inflammatory response was observed for flurbiprofen when given simultaneously with enalapril by comparing decrease in paw size. Results were expressed in \% reduction in paw size for every hour and were calculated for edema rate and percentage reduction. In vitro interaction studies carried out using HPLC and both the drugs were analyzed by assaying both drugs alone and in combination. The combination of enalapril and flurbiprofen showed increased activity of flurbiprofen as depicted by increase of $\%$ reduction and decrease in edema rate. It was also proved from AUC of the chromatogram of combine drugs. Since this study has certain limitation as a number of tested animals were small and the duration of anti-inflammatory response was checked for flurbiprofen alone and in combination with enalapril for few hours, further studies may be required to establish the strong relationship.
\end{abstract}

Keywords: In vivo in vitro, interaction, enalapril, flurbiprofen, HPLC

\section{INTRODUCTION}

Enalapril maleate chemically described as (S)-1-[N-[1-(ethoxycarbonyl) -3-phenylpropyl]-L-alanyl] -L-proline, (Z)-2-butenedioate salt , ${ }^{1}$ (Figure 1). It is an ester prodrug which after hydrolysis is converted to pharmacologically active enalaprilate, a specific competitive inhibitor of angiotensin converting enzyme ACE and inhibits the active sites of a zinc glycoprotein (ACE) blocking the conversion of angiotensin I to angiotensin II, whose levels are elevated in patients of hypertension ${ }^{2}$. Musculoskeletal and hypertension are two common coexisting problems for which NSAIDs and antihypertensive as are most commonly prescribed together ${ }^{3}$. Over the two decades the concern about drug interactions between NSAIDs and antihypertensive agents has been grown and several cases with hypertensive emergency have been reported after using NSAIDs in patients with previously well-controlled hypertension ${ }^{4,5}$.

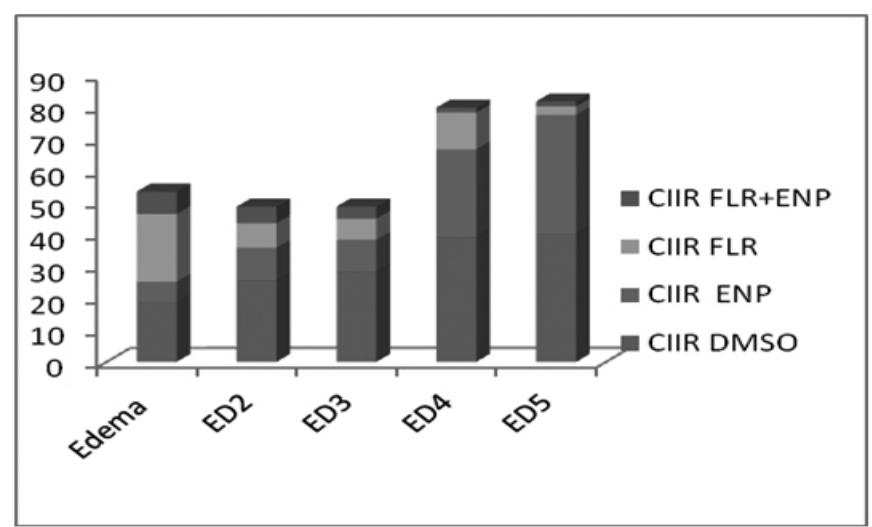

Figure 1 Edema rate in rat's paw after treatment

The combination of enalapril with other antihypertensive medicines may increase the antihypertensive effect when used especially in combination with diuretics ${ }^{6}$, hypoglycemic agents, beta-adrenergic blocking agents and methyldopa or calcium entry blockers potentiates the hypotensive effects enalapril ${ }^{7}$.

Reports suggest that NSAIDs may alter the antihypertensive effect of ACE inhibitors. The interaction should be given consideration in patients taking NSAIDs concomitantly with ACE inhibitors ${ }^{8}$. NSAIDs antagonize the blood pressure lowering effect of antihypertensive drugs. When lithium or antihypertensive agents are co-prescribed with NSAIDs, close monitoring is mandatory 9 . Lithium elimination may be reduced therefore the lithium levels of serum should be carefully compared if lithium salts are to be administered ,${ }^{10-12}$. NSAIDs including aspirin, reduce renal excretion of ACE inhibitors, with increase in circulating drug concentrations ${ }^{13}$.

Over the last two decades the concern about drug interactions between NSAIDs and antihypertensive agents has been grown and several cases with hypertensive emergency have been reported after using NSAIDs in patients with previously well-controlled hypertension ${ }^{4,5}$.

Taking this into account we have worked on a number of in vitro interactions of enalapril with hypoglycemic agents ${ }^{14}$ Lefunomide with NSAIDs ${ }^{15}$, enalapril maleate and $\mathrm{H}_{2}$-receptor antagonists ${ }^{16}$. To quantitate these interactions we reported simple and economical HPLC-UV methods for the quantitation of these drugs alone ${ }^{17}$ as well as in combinations ${ }^{18,19}$.Diabetic patients who take a combination of medications especially NSAIDS are prone to drug interactions, so it is necessary to study these interactions with respect to the pharmacokinetics of the combined dosage forms. Thus our research group reported a number of in vivo interactions of NSAIDS with leflunomide ${ }^{20}$, as well as hypoglycemic agents ${ }^{21,22}$ on Carrageenan Induced Inflammations.

In present paper the in vivo and in vitro interactions of enalapril with flurbiprofen on carrageenan induced inflammation rats (CIIR) has been studied to investigate the anti-inflammatory response of flurbiprofen with enalapril and alone. Earlier, we reported a facile method to quantitate enalapril with NSAIDS simultaneously using HPLC-UV technique which was used to study the in vitro interactions.

\section{MATERIALS AND METHODS}

\section{Animals}

Female rats weighing $180-250 \mathrm{~g}$ were used for the study and six animals in each group were housed in an animal room under standard temperature conditions i.e. at $21^{\circ} \mathrm{C}$.

Adjuvant induced inflammation

Adjuvant inflammation was induced in animals by a single intra dermal injection of 0.1 mili liter at the base of the foot. Solution prepared by carrageenan suspended in $0.9 \mathrm{NaCl}$ normal saline to the concentration of $1 \mathrm{gm} / 100 \mathrm{ml}$.

\section{Experimental design and drug treatment}

Rats $(\mathrm{n}=6)$ were randomly distributed into different groups received their respective treatment orally using $0.5 \mathrm{ml}$ dimethyl sulfoxide (DMSO) as vehicle one hour prior to inflammation induction table 1 .

The severity of inflammation was assessed by paw volume change. Swelling in paw and the state of the animals were monitored in each hour. Paw volumes were measured by using plethysmometer (Model 7140; Italy Varese,Ugo Basile,) on 0, 1, 2, 3, 4 and 5 hour of the designed experiment. The paw volumes were deliberated in test and control groups on zero and then on 
every alternate hour until 5 hour when the experiment ended. The dose regime of different drugs are given in table 1

Table 1 Dose of different groups.

\begin{tabular}{|c|c|c|c|}
\hline S. No & Groups & Treatment & $\begin{array}{c}\text { Dose (mg. } \\
\left.\mathrm{kg}^{-1}\right)\end{array}$ \\
\hline 1 & CII saline (Control) & Saline & --- \\
\hline 2 & CII ENP & Enalapril & 2.5 \\
\hline 7 & CII FLR & Flurbiprofen & 5 \\
\hline 11 & CII FLR+ENP & $\begin{array}{c}\text { Flurbiprofen+ } \\
\text { Enalapril }\end{array}$ & $5+2.5$ \\
\hline
\end{tabular}

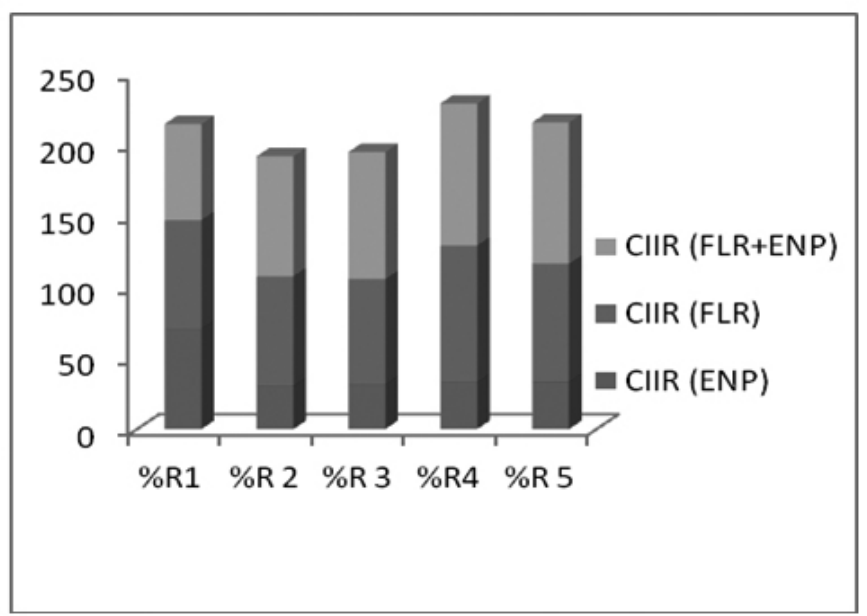

Figure $2 \%$ Reduction in rat's paw after treatment

\section{Statistical analysis}

The investigational outcomes were expressed as Mean \pm S.D of $n=6$ rats in each group. Edema rate and percentage reduction was also calculated by using one way analysis of variance using software SPSS INC. Tukey's posthoc test was conducted to determine group means differences with the level of significance chosen at $p<0.05$ or $p<0.005$.

In vitro studies

Stock solutions $\left(100 \mu \mathrm{g} \cdot \mathrm{mL}^{-1}\right)$ of enalapril, flurbiprofen were prepared in 80:20 methanol water individually. The ratio of solutions were mixed in 1:1 in flasks individually and kept on a water bath at $37^{\circ} \mathrm{C}$ for three hours with stirring. The samples were withdrawn after 30 minutes time interval for 3 hours and drug con-tents were filtered through a millipore filter $(0.45 \mu)$ and analyzed by RP-HPLC. The $\%$ availability of each drug was then calculated with respect their standard samples.

\section{RESULTS AND DISCUSSION}

Both antihypertensive and analgesic drugs are prescribed together since hypertension and co-existing musculoskeletal problems are two frequent conditions $[24,25]$. In order to identify the anti-inflammatory response of commonly used NSAIDs when administered concurrently with enalapril we used the group of rats with carrageenan induced paw inflammation. Inflammation was induced by carrageenan [26], which is acute, well-researched, non-immune and highly reproducible. In our study, an altered anti-inflammatory response of flurbiprofen was observed when given simultaneously with enalapril and comparing decrease in paw size (edema). Results were expressed in \% reduction in paw size for every hour and were calculated. The formula were used to calculate edema rate and percentage reduction.

Edema rate $(\mathrm{E} \%)=\mathrm{V}_{\mathrm{T}}-\mathrm{V}_{\mathrm{O}} / \mathrm{V}_{\mathrm{O}} * 100$

$\mathrm{V}_{\mathrm{O}}=$ Rat's hind paw volume before $1 \%$ Carrageenan administration.

$\mathrm{V}_{\mathrm{T}}^{\mathrm{O}}=$ Rat's hind paw volume at $\mathrm{t}$ hour.

Percentage reduction $(\mathrm{R} \%)=\mathrm{E}_{\mathrm{C}}-\mathrm{E}_{\mathrm{T}} \backslash \mathrm{E}_{\mathrm{C}} * 100$

$\mathrm{E}_{\mathrm{C}}=$ Edema rate of control group

$\mathrm{E}_{\mathrm{T}}=$ Edema rate of test compound at $\mathrm{t}$ hour.
Edema rate and percentage reduction data was also analyzed by using one way analysis of variance using SPSS INC. Tukey's post-hoc test was conducted to determine group means differences taking significant level $\mathrm{p}<0.05$ and highly significant $\mathrm{p}<0.005$.

Effect of enalapril on flurbiprofen induced anti-inflammatory response was studied by observing the groups CII FLR and CII FLR+ENP. Percent reduction by flurbiprofen was $3.0 \pm 1.0 \%, 72.01 \pm 1.01 \%, 79.53 \pm 0.5 \%, 67.20 \pm 1.06 \%$ and $66.07 \pm 1.0 \%$ in first, second, third, fourth and fifth hour respectively which was significantly low $(p<0.005)$ in first hour while significantly high $(p<0.005)$ in remaining hours. Simultaneous administration of flurbiprofen with enalapril in the group CII FLR+ENP showed percent reduction $67.61 \pm 0.29 \%$, $84.36 \pm 0.21 \%, 89.44 \pm 0.14 \%, 99.92 \pm 0.49 \%$ and $99.49 \pm 0.20 \%$ in first, second, third, fourth and fifth hour respectively which was significantly high $(\mathrm{p}<0.005)$ when compared to group CII FLR, showing that \% reduction was high as compare to flurbiprofen alone.

\section{In vitro interactions}

To develop a precise, accurate and suitable HPLC method for the simultaneous estimation of ENP and flurbiprofen different mobile phases were tried and the proposed chromatographic conditions were found to be appropriate for the quantitative determination. The short analysis time $(<5$ min) also enables its application in routine and quality-control analysis of the finished products. $\mathrm{pH}$ of mobile phase containing methanol: water (80:20) was adjusted to 2.9 with phosphoric acid while UV detection was performed at 225 $\mathrm{nm}$. The retention time for enalapril maleate was found to be 3.3 minutes, while that of flurbiprofen was 4.3 minutes (figure 3 ). The mobile phase was filtered on a 0.45 micron membrane filter and then sonicated for $10 \mathrm{~min}$; flow rate was set to $1.0 \mathrm{mLmin}^{-1}$. All determinations were performed at constant column temperature $\left(25 \pm 2^{\circ} \mathrm{C}\right)$.

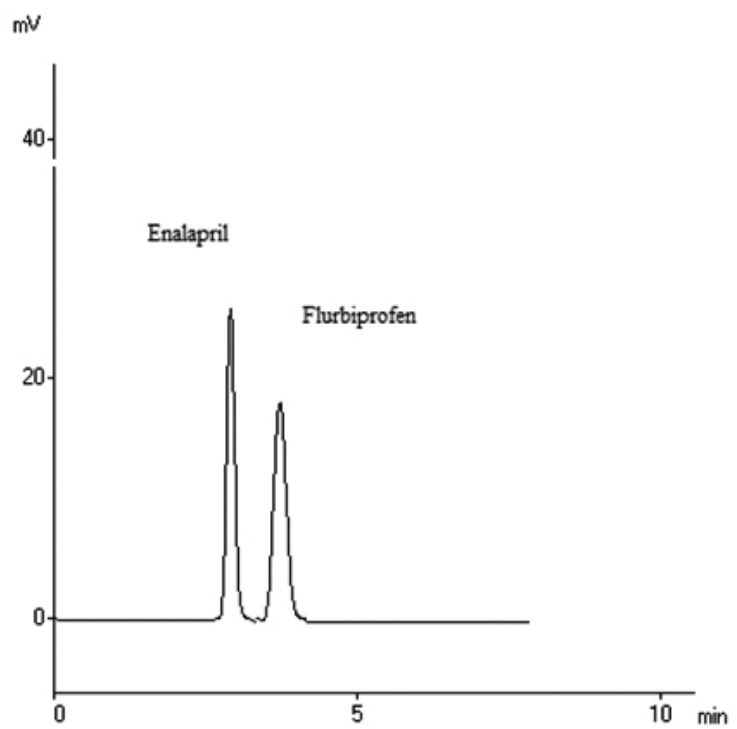

Figure 3: chromatogram of enalapril with flurbiprofen before interaction

The interaction results showed that the availability of flurbiprofen was increased in the presence of enalapril (figure 4). This suggested that for co administration of enalapril with flurbiprofen administration require continuous monitoring and a proper interval should be given to avoid such interactions.

\section{CONCLUSION}

The combination of enalapril and flurbiprofen showed increased activity of flurbiprofen as depicted by increase of $\%$ reduction and decrease in edema rate. It was also proved from AUC of the chromatogram of combine drugs. On the basis of clinical evidences that flurbiprofen can potentially interact with drugs that include b-blockers, ACE inhibitors, aspirin and corticosteroids. The drug interactions can metabolize the medicines differently than intended, increase risk of bleeding and make some drugs less effective, among other things. It would always be advisable to consult healthcare professionals about any flurbiprofen drug interactions, since this study has certain limitations due to limited number of tested animals as well as duration of anti-inflammatory response studied. 
Table 2 Edema rate in rat's paw

\begin{tabular}{|c|c|c|c|c|c|}
\hline Groups & Edema & ED2 & ED3 & ED4 & ED5 \\
\hline CIIR DMSO & 18.69 & 25.54 & 28.3 & 39.12 & 40.18 \\
\hline CIIR ENP & 6.4604 & 10.2933 & 10.0133 & 27.617 & 37.3564 \\
\hline CIIR FLR & 21.36 & 7.69 & 6.66 & 11.58 & 2.74 \\
\hline CIIR FLR+ENP & 6.9536 & 5.2224 & 3.7838 & 1.5333 & 1.5333 \\
\hline One Way & $\mathrm{F} 1=26320.1$ & $\mathrm{~F} 2=1596.1$ & $\mathrm{~F} 3=1580.3$ & $\mathrm{~F} 4=3975.5$ & $\mathrm{~F} 5=10292.8$ \\
\hline ANOWA $(\mathrm{df}=8,18)$ & $\mathrm{p}<0.005$ & $\mathrm{p}<0.005$ & $\mathrm{p}<0.005$ & $\mathrm{p}<0.005$ & $\mathrm{p}<0.005$ \\
\hline
\end{tabular}

Table $3 \%$ Reduction in rat's paw

\begin{tabular}{|c|c|c|c|c|c|}
\hline Groups & \%R1 & \%R 2 & \%R 3 & \%R4 & \%R 5 \\
\hline CIIR (ENP) & 70.3136 & 30.0973 & 31.0477 & 32.7781 & 33.03 \\
\hline CIIR (FLR) & 76.45 & 77.16 & 74.21 & 96.1 & 82.98 \\
\hline CIIR (FLR+ENP) & 67.6162 & 84.3648 & 89.444 & 99.9213 & 99.498 \\
\hline One Way ANOWA (df= 8,18) & $\mathrm{F} 1=136914.084$ & $\mathrm{~F} 2=9.713$ & $\mathrm{~F} 3=9.162$ & $\mathrm{~F} 4=256.157$ & $\mathrm{~F} 5=2883.266$ \\
\hline & $\mathrm{p}<0.005$ & $\mathrm{p}<0.005$ & $\mathrm{p}<0.005$ & $\mathrm{p}<0.005$ & $\mathrm{p}<0.005$ \\
\hline
\end{tabular}

Table $4 \%$ Availability of enalapril and NSAIDs by HPLC

\begin{tabular}{|c|c|c|c|}
\hline $\begin{array}{c}\text { Time } \\
\text { (minutes) }\end{array}$ & Enalapril & Flurbiprofen & $\begin{array}{c}\text { Enalapril + } \\
\text { Flurbiprofen }\end{array}$ \\
\hline 30 & 98.04 & 99.02 & 99.02 \\
\hline 60 & 107.4 & 95.31 & 99.31 \\
\hline 90 & 100.1 & 105.6 & 105.6 \\
\hline 120 & 100.1 & 98.3 & 105.3 \\
\hline 150 & 100.3 & 98.88 & 105.88 \\
\hline 180 & 101.2 & 100 & 105 \\
\hline Sig. (2-tailed) & t value2.674 & $\mathrm{df}=6$ & .037 \\
\hline
\end{tabular}

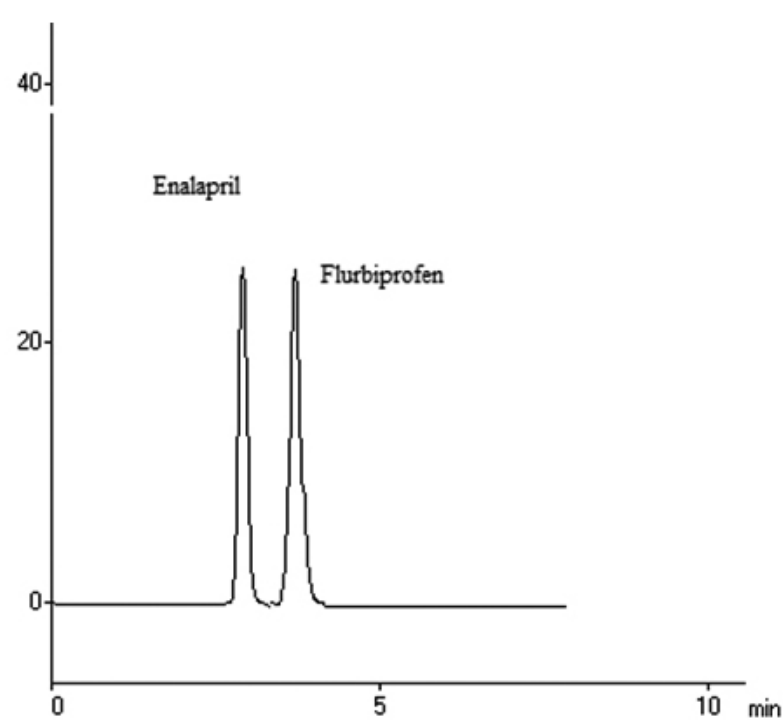

Figure 4: chromatogram of enalapril with flurbiprofen after interaction

Disclosure: Noting any conflicts of interest.

\section{REFERENCES}

1. Sweetman SC. Martindale: The Complete Drug Reference. ( $34^{\text {th }}$ edn) Pharmaceutical Press, London \& Chicago 2005; 900-901.

2. Dominic PI, Gerald SB. Analytical Profiles of Drug Substances. Academic Press, New York, 1987; 207-243.

3. Oates JA. Antagonism of antihypertensive drug therapy by nonsteroidal anti- inflammatory drugs. Hypertension 1988;11: II4-6.

4. Mousavy SM . Indomethacin induces hypertensive crisis in preeclampsia irrespective of prior antihypertensive drug therapy. Am J Obstet Gynecol. 1991; 165: 1577.

5. Sultana N, Arayne MS, Naveed S, Shamshad H. An RP-HPLC method for simultaneous analysis and interaction studies on enalapril maleate and $\mathrm{H}_{2}$ receptor antagonists. Acta Chromatographica .2009;21: 547-558.

6. Jiang XJ, Rourke MF, Zhang YQ, He XY and Liu LS. Superior effect of an angiotensin-converting enzyme inhibitor over a diuretic for reducing aortic systolic pressure. J Hypertens. 2007; 25(5): 1095-9.

7. Safar ME, Protogerou A. and Blacher A. Central blood pressure under angiotensin and calcium channel blockade. Hypertension. 2009; 54: 704706.

8. Morgan TO, Anderson AIE and MacInnis RJ. ACE inhibitors, betablocking drugs, calcium channel blocking drugs and diuretics for the control of elevated systolic blood pressure in the elderly: a double blind crossover study in previously untreated patient. Am J Hypertens. 2001;14 (13): 241-247.

9. Anthony GJ, Tuan VN and Richard OD. Do nonsteroidal anti-inflammatory drugs affect blood pressure, A meta-Analysis. Annals of Internal Medicine. 1994;121(4): 289 - 300 .

10. Das Gupta K, Jefferson JW and Kobak KA.The effect of enalapril on serum lithium levels in healthy men. J. Clin. Psychiatry. 1992; 53: 398400 . 
11. Finley PR, O'Brien JG and Coleman RW. Lithium and angiotensinconverting enzyme inhibitors: evaluation of a potential interaction. J Clin Psychopharmacol., 1996; 16: 68-71.

12. Sanjay S, Chandragiri MD, Pasol E and Rollin MG. Lithium, ACE Inhibitors, NSAIDs and Verapamil. Psychosomatics. 1998;39: 281-282.

13. Shionoiri H.Pharmacokinetic drug interactions with ACE inhibitors. Clin Pharmacokinet. 1993; 25(1): 20-58.

14. Sultana N, Naveed S and Arayne MS, Monitoring of In vitro Interaction Studies of Enalapril with Hypoglycemic Agents by LC-UV, Research and Reports in Medicinal Chemistry2013; 3:19-29 Dove Press open access to scientific and medical research . http://dx.doi.org/10.2147/RRMC.S32238

15. Sultana N, Arayne MS, Khan MM and Ali SN .Development of Liquid Chromatography-UV Method for Simultaneous Determination of Lefunomide and Four NSAIDs in API and Pharmaceutical Formulations: Its Application to In-vitro Interaction Studies Medicinal Chemistry,2013; 3(3): 262-270 http://www.omicsonline.org/ development- of-liquid-chromatographyuv-method-forsimultaneous-determination-of-leflunomide- 2161-0444.1000262.pdf

16. Sultana N, Arayne MS, Naveed S and Shamshad H, An RP-HPLC Method for Simultaneous Analysis of, and Interaction Studies on, Enalapril Maleate and $\mathrm{H}_{2}$-Receptor Antagonists. Acta Chromatographica. 2009; 21(4): 547-558. http://www.akademiai.com/content/d41k775k70n03203/

17. Naveed S, Sultana N and Arayne MS . HPLC-UV Method for the Determination of Enalapril In Bulk, Pharmaceutical Formulations and Serum. Analytical and Bioanalytical Techniques,2012; 3:130 doi:10.4172/21559872.1000130 http://www.omicsonline.org/21559872/2155-9872-3-130.php?aid=3913

18. Sultana N, Naveed S and Arayne MS. Facile and Manifest Liquid Chromatographic Method for the Simultaneous Determination of Enalpril maleate and NSAIDs in API and Pharmaceutical Formulations.Pharmaceutica Analytica Acta .2013; S2 004 http:// dx.doi.org/10.4172/2153-2435.S2-004 http://www.omicsonline.org/ ArchivePAA/SpecialissuePAA-S2.php
19. Sultana N, Arayne MS and Naveed S. Simultaneous Quantitation of Captopril and NSAIDs in API, Dosage Formulations and Human Serum by RP-HPLC. J. Chinese Chemical Society. 2010; 57(1): 62-67. http:// proj3.sinica.edu.tw/ chem/servxx6/files/paper 11137 1270711942.pdf

20. Arayne MS, Sultana N, Khan MM and Simjee SU. Leflunomide with Meloxicam on Progression of Rheumatoid Arthritis and its Associated Depression in AIA Rats. Clinical Pharmacology and Biopharmaceutics, 2014;3:1p 1000114

21. Naveed S, Sultan N, Arayne MS, Siddiqui R and Khan MM . In vivo Interaction Studies of ACE Inhibitors with NSAIDs on Carrageenan Induced Inflammation. Clinical Pharmacology and Biopharmaceutics 2013;2(1) • 1000108 doi.org/10.4172/2167-065x.1000108. http://www. omicsonline.org/ http://www.omicsonline.org/

22. Naveed S, Sultana N, Arayne MS and Akhtar M. In vivo Interaction Studies of Captopril with Flurbiprofen and Ibuprofen on Carrageenan Induced Inflammation. Open Access Scientific Reports.2012; 2:12 http:// dx.doi.org/10.4172/scientificreports.829

23. Sultana N, Naveed S and Arayne MS . Facile and Manifest Liquid Chromatographic Method for the Simultaneous Determination of Enalpril maleate and NSAIDs in API and Pharmaceutical Formulations. Pharmaceutica Analytica Acta 2013; 52004 http:// dx.doi.org/10.4172/2153-2435.S2-004 http://www.omicsonline.org/ ArchivePAA/SpecialissuePAA-S2.php

24. Johnson AG. NSAIDs and increased blood pressure. Drug Safety, 1997;17(5):277-89.

25. Roth SH. NSAIDs and gastropathy: a rheumatologist's review. $J$. Rheumatol. 1988;15: 912-919.

26. Gugasyan R, Clouston D, Mandel T and Wicks I. Prevention of splenic granuloma formation in adjuvant arthritis by 2-acetyl-4tetrahydroxybutylimidazole (THI). Immunol Lett. 1997; 58(3): 133-138 http://www.ncbi.nlm.nih.gov/pubmed/9293393 